\title{
Systems Approach to Develop a Conceptual Model of the Service Enterprise
}

\author{
Zaida Alarcón-Bernal1 ${ }^{(\mathbb{C},}$, Ricardo Aceves-García ${ }^{2}$ (), Arturo Fuentes-Zenón ${ }^{2}$ \\ ${ }^{1}$ Department of Biomedical Systems Engineering, National Autonomous University of Mexico, Mexico City, México \\ ${ }^{2}$ Department of Systems, National Autonomous University of Mexico, Mexico City, México \\ Email: zaida.alarcon@unam.mx, aceves@unam.mx, fuzenon@unam.mx
}

How to cite this paper: Alarcón-Bernal, Z., Aceves-García, R. and Fuentes-Zenón, A. (2019) Systems Approach to Develop a Conceptual Model of the Service Enterprise. Journal of Service Science and Management, 12, 697-713.

https://doi.org/10.4236/jssm.2019.126048

Received: August 14, 2019

Accepted: September 13, 2019

Published: September 16, 2019

Copyright $\odot 2019$ by author(s) and Scientific Research Publishing Inc. This work is licensed under the Creative Commons Attribution International License (CC BY 4.0).

http://creativecommons.org/licenses/by/4.0/

\begin{abstract}
Considering the characteristics and particularities of services such as inseparability, perishability and variability, which make them ephemeral and little tangible, non-storable, and non-patentable, we can have a clear idea of the complexity that exists in planning, operating and solving problems in service companies. This situation demands the use of a different vision to analyze and study these companies and their problems. Therefore, the systems approach is presented and used for the construction of a conceptual model, as a support framework to situate and organize our perceptions, fix the structure of the problem, delimit the area of interest and define the relevant and non-relevant aspects. With the systems vision, we have been able to use the three basic forms of planning for decision making (strategic, tactical and operative) in the construction of a conceptual model. The methodology used that integrates these three basic forms of planning is presented in a logical-formal guide for the construction of the conceptual model of the service company. This representation identifies the basic elements of a business model such as customers, value proposition, infrastructure and information for decision making, as well as their interactions. The model obtained is simple, relevant, and easy to understand and at the same time does not oversimplify the complex operation of a service company.
\end{abstract}

\section{Keywords}

Conceptual Model, Service Companies, Systems Approach, Service Science, Service System

\section{Introduction}

Services have gone from being a peripheral activity in an economy focused on 
manufacturing, to an engine of growth and innovation, driven by society. This transformation has been fully recognized by the flourishing and innovation in services, as well as by studies and research on services, aimed at deepening their understanding and supporting the development of services as a sector and as a concept [1].

Due to the characteristics and particularities that have the services such as being little tangible, inseparable, perishable and variable [2], service is an ephemeral product, created and consumed simultaneously and therefore not storable. In addition, services are ideas and concepts, so their outputs are sensations and experiences, and therefore, innovations in service are not patentable.

These assertions give us a clear idea of the complexity that exists to plan, operate and solve problems in service companies. This situation highlights the need to use a different approach to analyze and study this type of companies and their problems. This consideration is strengthened by pointing out that complex problems include heterogeneous factors that go beyond the vision of any conventional discipline. Therefore, an integrative and interdisciplinary vision as the systems approach is demanded, that presents emerging properties that cannot be deduced from their components.

The main objective of this work is to show that some contributions of Systems Theory are applied to better understand complex phenomena and promote different points of view and paradigms in emerging areas such as Service Sciences, as well as acting as foundation for managing and planning modern dynamics in any type of organization, in terms of integration of resources, interaction of systems and viable behaviors, through the formulation of the conceptual model.

This article is structured as follows: In the first section we present the need to use the systems approach to analyze some object of study, considering the complexity generated by the interrelation of its elements and the interaction of the object itself with its environment. It also establishes the need to have a global vision of these objects or problems to avoid a partial analysis, so it is important to have "a vision of the world" through which the way in which it interprets the object or problem is made explicit. The second section presents the three basic forms that have been identified in the literature for building the system or conceptual model: the structural approach, the functional approach and the black box approach. The third section presents the methodology used to integrate the three basic forms above integrated, to relate the what for, how and why, in a logical-formal guide for the construction of the conceptual model. The fourth section presents the conceptual model developed for service companies, where the basic elements of a business model can be identified: customers, supply, infrastructure and information for decision making from the systems viewpoint. Finally, we present some works related to the use of the systems approach and the development of some conceptual model, to finally establish our conclusions.

\section{Related Works}

The awareness and generation of knowledge about service businesses is a very 
recent field of research and application, which began in 2004 under the guardianship of IBM developing the concept of Service Science [3]. The concept of Service System has provided people interested in this field of knowledge a new way of looking at services as a set of interactions between suppliers and consumers that together create value for themselves, as a system, considering as a final objective, the application of scientific knowledge in the design and improvement of service systems for business and social purposes.

It was identified through literature that systemic thinking provides some of the necessary foundations for Service Science [4] in general and for service systems in particular. According to this perspective, most authors have limited themselves to expressing generalities of the concept of systems and its immediate implications or to using methodologies applied in other fields of knowledge, without offering precise guidelines for the analyst on how to define the system of interest for decision making.

White [5] establishes that Business Process Modeling Notation (BPMN) is a technique for formally modeling and describing how business processes are structured and to represent the detail of those processes. In SEAM (Systemic Enterprise Architecture Method), the approach is to build a business concept as a nested hierarchy of systems. Therefore, the modeler is interested in conceptualizing the systems that the company contains, and those that contain the company. Thus, emphasis is placed in understanding the systems, defining their limits, the services provided by the set of systems (black box view of the system) and the processes that these services implement in the system as a whole (white box view of the system). In SEAM the behavior of the system is specified by modeling the processes in the systems. We could have one process in the market, one in the company, one in the IT department, one in the IT applications. In BPMN, there is usually a process that merges all these levels and abstracts some of them. In short, SEAM is a system-oriented modeling technique, while BPMN is process-oriented.

Flood and Zambuni [6] attempt to contribute a detailed description, discussion and critique of a Viable Systems Diagnosis application to an important group of tourism services. The approach of Beer [7] is well known and widely discussed and referenced in scientific literature. However, case studies documenting their use are much scarcer and are often limited to general outlines of a small practical use.

Godsiff et al. [8] are intended to describe the possible application of Ashby's Exigent Varieties Act and its consequences [9]. Generally stated and understood as "only variety can destroy variety" [10], it uses system concepts to examine the impact of external disturbances on the viability of an organization. The work begins with a brief discussion of the nature of the service and suggests that a consensus is emerging that definitions should focus, first, on the process rather than the product and, second, on the interaction and relationships between the customer and the producer. A brief overview of some of the concepts of systemic 
thinking (the study of complex and adaptive sets) and how it has been applied to the study of management and operations based on the work of Forrester and Beer [11] is provided.

Barile et al. [4] mention the potential benefits of using network theory and VSA for service science. They also compare inputs and views on the services, marketing and management of these different frameworks. The concept of service system has allowed researchers to visualize a service as a set of providers and consumers who interact and jointly add value to themselves; therefore, when the company loses the aspects that allow an observer to differentiate it from the other companies, the corresponding system disappears for the observer in question and for the others.

In [3], the authors compare the fundamental concepts of intelligent service systems and viable service systems, highlighting the potential mappings between service science and the principles of systems science.

Böttcher and Fähnrich [12] establish that an important aspect in the field of service science is the service modeling; however, there is not one-size-fits-all approach to modeling. In this sense, the authors analyze the literature of service science and existing modeling approaches. Based on this analysis, they identify the concepts needed for service modeling. In their work they specify a semi-formalized meta-model that understands the concepts found and in order to have a more applicable meta-model, the authors transfer it to the technical space Eclipse Modeling Framework [13]. The authors establish that in order to increase the viability of their meta-model, they define four dimensions in which they group the identified concepts. These dimensions are component model, resource model, product model, and process model. They all focus on different aspects of a service. In general, they consider that their work encompasses existing approaches and presents a formalized and well-structured meta-model in the domain of service modeling that can be used as a starting point for future research in the area of service modeling. As the meta-model is quite complex with many concepts, they state that it is necessary to perform an aggregation in future works. In addition, some of the concepts presented put much of the responsibility on the modeler. It is therefore necessary to specify these concepts with more detail so that the space for interpretation is limited.

Golnam et al. [14] establish that recent research has explored the principles of the viability of service systems based on systems vision, considering the perspectives of Systems Theory and Cybernetics, in particular Stafford Beer's (VSM) model of viable systems. However, based on Banathy and Jenlink [15], Systems research encompasses more than just Systems Theory and includes domains such as Systems Methodology and Systems Philosophy. Based on existing literature, they state that their work has the following particularities: 1) it is based on a systems philosophy in which the authors define what they consider to be viability and 2) it involves a systems methodological approach to analyze the viability of a system of services or to design a viable system of services. This is achieved 
through the application of the Systemic Enterprise Architecture Method (SEAM). The SEAM technique is based on systemic principles and incorporates VSM conceptualizations. The method presented in this paper can be categorized as a problem structuring method (PSM). PSM help decision-makers structure problems rather than solve them by identifying an agreed framework for their problem. The authors apply SEAM to model a specific utility in Geneva, Switzerland, in order to understand how a system of services maintains its identity and remains viable in its environment.

Maglio and Spohrer [16] use four basic principles of service science. The authors systematically explore the design of the value proposition as a type of business model innovation. They believe that service science combines organization and human knowledge with business knowledge and technology to categorize and explain service systems, including how they interact and evolve to create value. Their objective is to apply a scientific approach to advance in the design and innovation of service systems. Considering as a basis the dominant logic of service, which provides perspective, vocabulary and assumptions upon which to build a theory. They indicate that the basic theoretical construction is the system of services, entities that are the dynamic configuration of four types of resources. The basic principles focus on how value is calculated within and between entities, how interaction is based on access to resources and their capabilities, and how value calculation and interaction depend on symbol processing and language guided by mutually agreed value propositions. In this context, they state that service science can inform and accelerate the design of value propositions by systematizing the search for adaptive advantages that improve existing offerings, create new offerings or create the ecosystem of value creation.

Polese et al. [17], in their work they establish that, in contemporary dynamic markets, management approaches based on systems theory have acquired increasing importance, which has led companies to value a holistic view to challenge environmental changes. In particular, the Viable Systems Approach (VSA) symbolizes this holistic view of companies, introducing some innovative concepts that renew traditional management paradigms in terms of decision-making. Simultaneously, in the field of service science research, service sciences can be interpreted as a global framework that investigates the efficiency of companies, which in turn are designed as service systems; there are numerous points of convergence between the service science research stream and the VSA. Therefore, they indicate that their work aims to combine the two, highlighting common characteristics, in order to propose ideas for an integrated and shared macro-level conceptualization of service systems and intelligent service systems. The main objective is to demonstrate existing opportunities and capture emerging contributions to advances in Service Sciences. This can be achieved by encouraging different viewpoints and paradigms, such as VSA, thus avoiding a possible "lost call" from the community of service science researchers around the world. 


\section{Systems Theory, an Approach to Understand Complex Phenomena}

\subsection{Systems Approach}

Today's business scenarios are characterized by globalization, social and political developments, technological innovation and other factors that signify increasing complexity. This phenomenon, examined by many disciplines, refers to the inability of organizations to act in an unstable context, in which the rules are not in the forefront and the risk is very high. To cope with this uncertainty, companies must expand their boundaries and establish other ways to deal with their problems.

Under this perspective, the systems approach to problem solving allows us to face increasingly complex multiple situations, where the elements or parts of the object under study are intimately interrelated and the object itself interacts in the environment with other objects.

Systemic thinking emerges as a response to the failure of mechanistic thinking and vitalism in explaining biological phenomena and complex problems. According to the systemic thinking, a "system" is a complex and highly interconnected network of parts that presents synergistic properties, in which the whole exceeds the sum of its parts [18]. This consideration is strengthened by pointing out that complex problems include heterogeneous factors that go beyond the vision of any conventional discipline. Therefore, an integrative (and interdisciplinary) vision such as this approach is demanded, as it presents emerging properties, which cannot be deduced from its component [18].

The systems approach has found in the field of problem solving a very fertile ground for its development and dissemination. As established by Fuentes-Zenón [19], in general, the approach has had three basic lines of work, the first on the development of concepts to study reality as a system (formulation of the conceptual model); the second on the development of methodological schemes to guide the problem-solving process in its different phases; and the third on the development of techniques and models to support the decision-making, as well as to obtain and analyze the required information. The last two lines have received the greatest attention in literature, with the first lagging behind, despite its importance. It is not possible to elaborate an adequate description of the functioning or dynamics of a phenomenon, problem or object if there is not an adequate description of the main elements involved and their relations. Therefore, who can solve a problem when they do not have the necessary elements to say what is relevant and what is irrelevant, to fix the criteria and restrictions to be observed, and even more, when they do not have the capacity to decide in which fields they need more information and study?

\subsection{Complexity}

The common reasoning to justify the need for the systems approach is to point out that, at present, multiple problems are faced have the tendency of becoming 
increasingly complex objects of study. This complexity is due to the fact that the elements or parts of the object under study are intimately interrelated and that the object itself interacts in the environment with other objects.

From the above, it can be established that the proper functioning or overall efficiency of the object is beyond the correct design or isolated performance of the parts, since it also influences the way in which they interact and adjust to each other and to their environment.

Ackoff [20] goes beyond this reasoning based on common sense and highlights the existence of two different forms of thought: analytical and systemic. According to this author, the consequence of the growing technological development associated with factors such as greater social complexity, they have resulted in changes being generated with greater speed and frequency. In this context, new concepts and ways of seeing the world emerge that configure systemic thinking, which complements and partially substitutes the conventional form of analytical thinking.

When the whole cannot be separated into independent parts, it introduces cause-effect relationships (mechanicism), causes that are necessary and sufficient for the effects (determinism), relationships that are generally linear and two-variable. But when the variables are multiple and the relations are not linear, this reductionist-mechanicist procedure is complicated and invalidated by the existence of interaction between the parts, since these cannot be studied separately [19].

In the systems approach as an alternative to the cause-effect relationship, a producer-product relationship is adopted. In this relationship a producer is necessary, but not enough for the product, as other factors also influence. This type of relationship makes it possible to introduce aspects such as agency, choice and objectives, in such a way that the phenomena are not only explained by what causes them, but also by the effect they are intended to produce (teleology). Consequently, while a system is structurally divisible, it is indivisible from a functional perspective on the assumption that the sets are interdependent. Therefore, in the systemic thinking there is a tendency to see systems as part of larger systems (expansionism) and related to other systems, rather than as a whole to be separated in parts. And what the analytical thinking considers the whole, in the systemic thinking becomes a part, and the doctrines of reductionism and mechanicism are replaced by those of expansionism and teleology [19].

\subsection{Reality as a System}

The fundamental argument in favor of the systems approach is the need to have a global or total view of the problems, in order to avoid the partial analysis of the situation, which invalidates the interaction between the parts.

However, Churchman [21] warns that in that "global vision" there is a hint of arrogance that should not be admitted without formulating a challenge, for which it is worth thinking: what happens when faced with a highly complex 
problem such as services, transport, poverty, etc. Problems where a series of disorganized images and ideas emerge, such that it is not easy to determine where the problem begins and ends, what is cause and what effect. Moreover, problems can be perceived and approached differently by different actors.

It must be considered that the idea of totality, when taken to the field of problem solving, is misleading and even fanciful, because it is not possible to reach the global vision that is supposed.

\subsection{The Vision of the World}

About the role of the subject, we must keep in mind that the same reality can be interpreted in different ways by different people and, even more, the same person could think differently in another place or at another time. This happens because objects are not projected into an empty mind, but the observer possesses certain values, experience, training and interests that influence his judgments and determine him to see what he sees [19].

In order to deal with this factor operationally, the concept of "vision of the world" [22] will be used, to make explicit the different ways in which the same object or problem is interpreted. Although it is clear that given a specific problem, only certain representations are of interest.

This is very important because it follows that in solving problems it is neither necessary nor sufficient to strive for obtaining "the total or the most complete description of the object", but that the effort must be directed to identify the aspects of relevance, though with the warning that the relevance is given by the kind of problem being addressed and therefore it is not an intrinsic property of the object.

From the previous sections it is possible to distinguish three ways in which the word system is used: The term is used to refer to objects of research or direction (a company, transport, economy, a dam, etc.), which we will call object or object system. System is also used to refer to the representations of such objects, which some authors call focal object, object of study, constructed system or conceptual model. Finally, system is used to refer to the instruments, procedures, theories, techniques, etc. that are used by the subject to investigate the object and for the construction of the conceptual model.

In this work we adopt the second denomination. The conceptual model is considered to be a graphic, written or mental representation that is developed as a support to locate and establish our perceptions, determine the structure of the problem, delimit the area of interest and specify the relevant and non-relevant aspects [19].

Consequently, through this logical-formal strategy, a guide can be established that serves to guide the analyst or decision-maker. It can be used as a tool to investigate a specific context and have the possibility to introduce some change and improve their performance. This is important because in order to formulate and solve problems, it is necessary to have the necessary elements to define what 
is relevant and what is irrelevant, to establish criteria and restrictions to be observed, and to decide in which fields more information and study are required. In this way it is possible to establish that we have a practical instrument from which it will be possible to build a conceptual model for service companies. This is developed in the following section.

\section{The Conceptual Model a Strategy for Structuring Complex Phenomena}

The conceptual model is a graphic, written or mental representation that is elaborated as a support framework to situate and order our perceptions, fix the structure of the problem, delimit the area of interest and define the relevant and non-relevant aspects. The raison d'être of conceptual models is clear, because when facing a new situation, there is an urgent need to formulate an image or representation that helps to understand its nature and explain its behavior. Conceptual models are important because they oblige to organize knowledge, to be clear about what it is about to study, observe and measure, allowing better communication between the different participants and providing a more solid basis for debate when it is required.

The literature identifies three basic forms of planning and decision making that are useful for the construction of the system or conceptual model: the structural approach, the functional approach, and the black box approach, the characteristics of which are presented in this section.

\subsection{Structural or Operational Approach}

If it is assumed that a system is a set of interconnected elements that form a totality, it is almost immediately concluded that the following would suffice to know the object and explain its properties:

1) Identify the parts or components of the object system;

2) Know the characteristics of the parts;

3) Establish the pattern of relations between the parties;

4) Gather this information and from there derive the properties and behavior of the total system.

However, when trying to follow this procedure in any specific case, it turns out that the volume of information demanded grows explosively, thus moving away from any practical purpose.

Despite of these disadvantages, we cannot forget that the knowledge of the elements and attributes is essential to explain the behavior or properties of the object, the crucial aspect is to define which elements and which properties we must be considered.

\subsection{Black Box or Strategic Approach}

According to this approach, the object of study is seen as an entity that receives certain inputs and transforms them into a product, using for its representation a 
block diagram called a black box, because at the beginning level of analysis, it does not establish how the transformation process is carried out, that is, "what does the box contain". This form of representation, despite being very simple, is very useful in solving problems, since it leads us to think about the interaction of the object with its environment and thus to deal with such important issues as: the validity of the objectives, the viability of the system in accordance with respect to the availability of inputs, the existence of development opportunities, the impact of certain changes, and so on. In addition, it establishes a "vision of the world" for the analysis and solution of problems.

It is essential to emphasize the importance of this conception, since we tend to abound in detail without first understanding the most general and significant aspects, which could be motivated by the prevailing reductionist mentality. On this particular point, pay attention to what those people who are qualified as having a great vision do and you will notice that they avoid the details before achieving a general understanding of the problem, thinking precisely in terms of black boxes: what is sought and why, what affects and how, etc.

\subsection{Functional or Tactical Approach}

Under this perspective, the object of study is visualized as a process, that is, as a set of activities required to fulfill a function or purpose; the production of a good or service, the launch of a new product or service, the operation of a transportation system, the redesign of a curriculum, etc. With this approach, the links correspond to logical dependence connections or to flows of information or materials between activities and with the exterior of the system. Each activity can be fragmented into a set of sub-activities, in the same way that the function of the system can be seen as an activity of a larger system, which leads to talk of sub-systems and supra-system, respectively.

Once the system of activities has been formulated, this model can be used as a basis for developing other types of representations. For example, if the purpose is to design or evaluate an information system, for each activity or sub-activity the following will be asked: what information is required? In what form? From what source? How often? The resulting conceptual model will represent information flows with these characteristics.

When the purpose is to improve the structure and processes of a company, for each activity or sub-activity the question will be asked: What activities are related? It is convenient that they are under a line of command? In which areas should authority and responsibility be delegated? The level of detail of the systems of activities and the type of questions to be asked are directly related to the problem or problems to be solved, and the examples presented are only intended to illustrate the role and mode of use of the system of activities.

According to this tactical or functional vision, conceptual models are formulated considering, in the logical sense, what activities are required to fulfill the proposed function and through what means or with which resources they could 
be executed, allowing to investigate reality in a selective manner in search of what is wrong and why. This also makes it possible to investigate which part or which element is the cause or, if considered more appropriate, to break the activity into sub-activities.

The main advantage offered by this conception is to avoid bulky data collection or endless loops (system, activities, sub-activities, parts, elements, relationships, attributes, etc.) since, as stated above, it is not necessary to know in detail all activities and only the part of the system "uncovers" those activities that do not operate properly.

With respect to their disadvantages, the fact stands out that organizations are designed and operated according to many purposes and in many ways, so that they can also be interpreted in many ways, an aspect that escapes the vision of this mono-functional and mono-valent conception.

\section{Logical-Formal Strategy for the Construction of the Conceptual Model}

Using a logical-formal strategy in which the systems vision is articulated makes it possible for observers such as professionals, managers, academics and others to understand and structure a phenomenon completely. They not only break the object of study into elementary parts and then improving it (as reductionism does), but also establish a "vision of the world" for their analysis, through which, with a logical strategy, they determine the activities required to fulfill the proposed function and the means or resources with which it could be executed, which allows them to investigate reality in a selective manner in search of what is wrong and why.

Consequently and considering that it would not be possible to elaborate an adequate description of the functioning or dynamics of a phenomenon, problem or object, if a proper description of the main elements involved and their relations is not made, it can be said that it is important to have a logical-formal observation strategy that integrates the previous basic approaches for the construction of the conceptual model. In fact, the structural conception is useful to explain the "reason" of certain properties of the object, the functional helps to understand "how" it operates and the black box clarifies the "purpose", that is, defines the role that the system plays in the environment in which it develops.

From this, a procedure is developed that synthesizes these three basic forms, which relate "what for, how and why" in a guide for the construction of the conceptual model, and explains its organization based on the following reasoning [19].

It has been established that in the structural conception-based on knowing the elements of the object system, relations and attributes-the main difficulty is defining which elements and which attributes must be taken into account to explain the properties and behavior of the object system. Such difficulties are reduced if the functional or tactical conception precedes the structural one, since 
in the light of the good or bad behavior of each activity it is possible to discriminate which parts need to be known in greater detail and which do not. Furthermore, given the multifunctional and multivalent nature of objects, it is impossible to develop a system of activities that completely covers them, so the black box concept is useful to specify which functions are of relevance and from what point of view or what world view they will be studied.

- First stage (vision of black box or strategic): Establish the vision or visions of the world from which the problem should be analyzed, for this we ask: Why is the fulfillment of each function considered important? Define which of the functions, among those attributed to the object system, are related to the problem proposed.

- Second stage (functional or tactical vision): Define the system of activities required to fulfill the function attributed to the object system, considering the adopted vision of the world. Establish the interconnections between activities and with the exterior of the system. Develop the system of activities in subsystems until reaching the required level of detail.

- Third stage (structural or operative vision): Once the systems and subsystems of activities to analyze are established, they will be used as a base to define which properties and which elements must be observed and studied to explain the behavior of the system.

\section{The Conceptual Model for the Service Company}

Services are inseparable, perishable and variable, these characteristics make them ephemeral, for what they are created and consumed simultaneously and therefore cannot be stored. This situation makes critical the administration and operation of this type of companies. These statements give us an idea of the complexity that exists to plan, operate and solve problems in service companies. This context demands the use of a different vision for the analysis and study of these companies and their problems.

We will start from the meaning of the conceptual model as a form of graphic, written or mental representation that is developed as support to locate and establish our perceptions, determine the structure of the problem, delimit the area of interest and specify the relevant and non-relevant aspects. Due to the characteristics of the service and the complexity for its planning, management and operation, the action strategy indicated to analyze and intervene this type of companies and their problems are the systems approach.

We propose to generate a conceptual model that is simple, relevant, easily understandable and at the same time does not oversimplify the complex operation of a service company, through the three levels of planning and decision-making of the systems approach, which are: strategic level (black box, "what will we do"), tactical level (functional, "how we will do it") and operational level (structural or measurement). And as a result of the analysis, we propose the following conceptual model (Figure 1). 


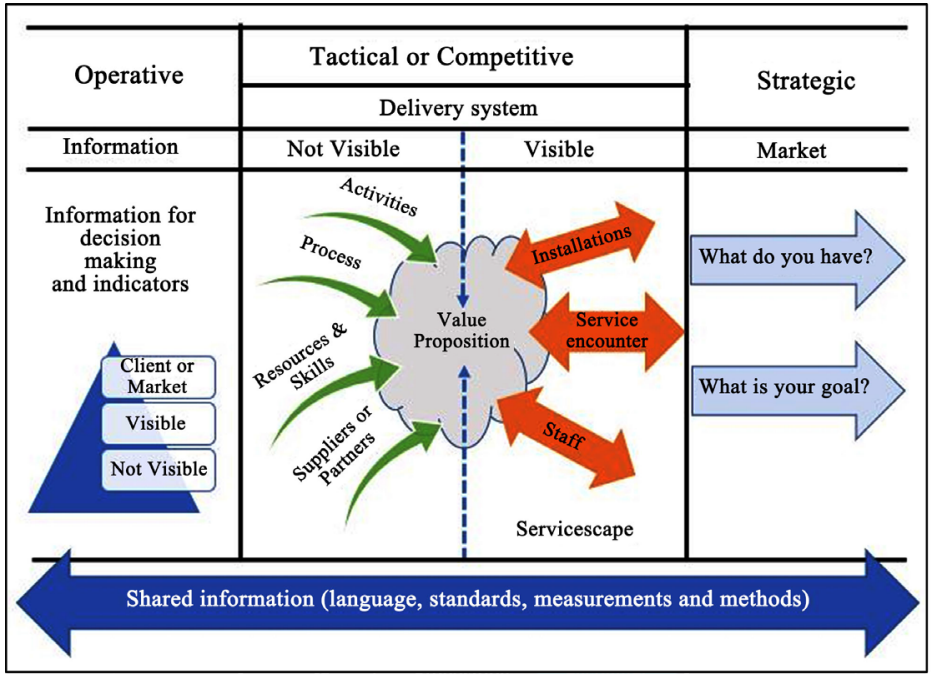

Figure 1. Conceptual model of the service company. Source Own elaboration.

With this conceptual model for the service company, it is possible to identify the integration of the basic elements of a business model: clients, value proposition, infrastructure and information for decision making, from the systems vision. It also helps to identify the interaction between the different stages and actors that compose them, their relationship with the environment where they are developed and the possibility of measuring their performance.

\subsection{Strategic or Black Box Vision}

With this approach should be established the interaction of the service company with its environment and with it, to address such important issues as: the validity of objectives in the market, the viability of the service offer according to the availability of inputs, the existence of development opportunities in certain market segments, the impact of changes in service delivery. It is necessary as well to define the target market or the different groups of people or entities which will use the service. With the questions: "What do you have?", "What is your goal (aspiration)?", it is possible to define the target market segments for the service, based on the specific needs of the target customer.

In conclusion, the key questions are: What do you have? What is your goal (aspiration)? And should be identify the models, techniques and methodologies that should be used to achieve the required answers should be identified.

\subsection{Tactical, Competitive or Functional Vision}

This perspective visualizes the company as a service delivery system, that is, as a set of integrated processes to fulfill a function or purpose for the generation of the service, or for the launch of a new service, or for the operation of the delivery system, etc. Therefore, it is necessary to define the system of activities that are needed to fulfill the function attributed to the service under study, bearing in mind the adopted world vision, establish the interconnections between activities and with the exterior of the system, and breaking the system of activities into 
sub-systems until reaching the required level of detail.

The service system is the way in which the business prepares and conducts itself in the service meetings for the co-creation of value. It includes facilities and their distribution, technology and equipment used, value proposition processes, resources, key activities and skills, basic collaborators, shared information, employee job descriptions, and the roles they and the customers play during a service encounter, always considering the two parts of the service, the front area or visible to the customer and the rear area or not visible to the customer.

A service system must be designed to achieve maximum customer satisfaction. As most service concepts can be copied by competitors, this delivery system must be well designed in such a way that it is not easily duplicated.

Consequently, a service delivery system should be designed and built using mathematical models and lean techniques to achieve maximum customer satisfaction and avoid easy duplication of the system.

\subsection{Measurement, Operational or Structural Vision}

The necessary information must be generated for the decision-making, which implies costs and revenues, in addition to the necessary indicators on efficiency, quality and productivity for the improvement and regulation of the service.

Since performance measurement is a multidimensional problem and there is no single way to measure that can capture the full complexity of the system, Aronsson and Andersson [23] suggest a division based on the purpose of KPI measurement (Table 1). This division is based on the purpose of the evaluation, this is, to measure process performance or measure functional performance, combined with an engineering approach, to focus on physical and financial measures of KPI.

Process performance indicators measure the outputs of physical and administrative processes, basically the order and delivery process, that is, the transformation within the service system. Representative indicators are time of delivery, service delivery and cash, while functional performance indicators for a function are entry to the function or between functions. This means that these measures, unlike process performance measures, often have a unique perspective. The typical measures are costs, productivity and utilization, i.e. measures from the structural perspective within the service system.

Table 1. Performance of processes and functions.

\begin{tabular}{lll}
\hline & - Process performance & \\
KPI & - Delivery time & - Utilization \\
physical & - Customer service & - Productivity \\
& - Process flexibility & - Turnover rate \\
KPI & Complicated, although there are & - Budgets \\
financial & some methods such as & - Costs of resources used \\
& activity-based costing & - ROI \\
& Process performance & Function performance \\
\hline
\end{tabular}

Source: Adapted from [23]. 
Indicators should capture both: process performance throughout the process and across functional boundaries and perspectives. The division of measurements also points to the fact that effective and efficient service companies require both processes (transformation) and functions (structure) that are efficient and effective.

Then, the physical and financial KPI that services companies should use to monitor processes and functional performance should be identified, as well as feedback to regulate their behavior and reduce the differences between actual and desired performance.

\section{Conclusions and Extensions}

Considering the particularities of services, the systems approach is used to incorporate another way of analyzing service companies and their possible problems.

A logical-structural approach is used that integrates the three basic forms for the construction of the system or conceptual model: strategic level (black box, "what we will do"), tactical level (functional, "how we will do it"), and operational level (structural or measurement activities) to develop a product of practical importance to guide the analyst or decision-maker. This tool serves as an instrument to inquire into the reality that one wishes to perform and to have the possibility of introducing some change and improving performance.

A conceptual model for service companies is proposed. This model is simple, relevant, easily understandable, and at the same time does not oversimplify the complex operation of a service company. Through this conceptual model it is possible to identify the integration of the basic elements of a business model: clients, value proposition, infrastructure and information for decision making, from the systems vision. It is also possible to recognize the interaction between the different stages and actors that compose them, their relationship with the environment where they are developed, and the possibility of measuring their performance, through the three levels of planning and decision making of the systems approach.

As extensions, a series of questions in the three levels of decision are presented as ways to follow in the exploration of the topic, whose answers will lead to methodological tools and mathematical models, useful for administrators and operators of the service companies. In this way, it is necessary to identify, develop or modify mathematical models, lean techniques and other methodologies applicable to the service company in order to answer the questions posed.

It should be noted that due to the multivalent and multifunctional characteristics of the objects of study, the conceptual model is only an option to interpret an object and, therefore, only serves as an instrument to investigate problems and study the possibility of introducing some change. Therefore, the proposal for a conceptual model presented in this research for service companies is not aimed at any one in particular; it is of a general conceptual and schematic nature 
for this type of companies, and therefore does not incorporate appropriate support issues for each decision-making level.

\section{Acknowledgements}

This research has been funded by National Autonomous University of Mexico as the project PAPIIT IN116217 Optimización de los procesos y operaciones en las empresas de servicios.

\section{Conflicts of Interest}

The authors declare no conflicts of interest regarding the publication of this paper.

\section{References}

[1] Maglio, P., Srinivasan, S., Kreulen, J. and Spohrer, J. (2006) Service Systems, Service Scientists, SSME, and Innovation. Communications of the ACM, 49, 81-85. https://doi.org/10.1145/1139922.1139955

[2] Hartman, D. and Lindgren, J. (1993) Consumer Evaluations of Goods and Services: Implications for Services Marketing. Journal of Services Marketing, 7, 4-15. https://doi.org/10.1108/08876049310038364

[3] Barile, S. and Polese, F. (2010) Smart Service Systems and Viable Service Systems: Applying Systems Theory to Service Science. Service Science, 2, 21-40. https://doi.org/10.1287/serv.2.1_2.21

[4] Barile, S., Spohrer, J. and Polese, F. (2010) Editorial Column-System Thinking for Service Research Advances. Service Science, 2, 1-3. https://doi.org/10.1287/serv.2.1_2.i

[5] White, S.A. (2004) Introduction to BPMN. BPTrends.

[6] Flood, R. and Zambuni, S.A. (1990) Viable Systems Diagnosis. 1. Application with a Major Tourism Services Group. Systemic Practice and Action Research, 3, 225-248. https://doi.org/10.1007/BF01062730

[7] Beer, S. (1984) The Viable System Model: Its Provenance, Development, Methodology and Pathology. Journal of the Operational Research Society, 35, 7-25. https://doi.org/10.1057/jors.1984.2

[8] Godsiff, P. (2010) Service Systems and Requisite Variety. Service Science, 2, 92-101. https://doi.org/10.1287/serv.2.1_2.92

[9] Ashby, R. (1964) An Introduction to Cybernetics. Chapman \& Hall Ltd., London.

[10] Ashby, R. (1969) Self-Regulation and Requisite Variety. Penguin, Baltimore, 105-124.

[11] Forrester, J. (1958) Industrial Dynamics. A Major Breakthrough for Decision Makers. Harvard Business Review, 36, 37-66.

[12] Böttcher, M. and Fähnrich, K.-P. (2011) Service Systems Modeling: Concepts, Formalized Meta-Model and Technical Concretion. In: The Science of Service Systems, Springer, Berlin, 131-149. https://doi.org/10.1007/978-1-4419-8270-4_8

[13] Budinsky, F., Steinberg, D., Ellersick, R., Grose, T. and Merks, E. (2004) Eclipse Modeling Framework: A Developer's Guide. Addison-Wesley Professional, Boston.

[14] Golnam, A., Regev, G. and Wegmann, A. (2011) A Modeling Framework for Analyzing the Viability of Service Systems. International Journal of Service Science, Management, Engineering, and Technology, 2, 51-64. 
https://doi.org/10.4018/jssmet.2011070104

[15] Banathy, B. and Jenlink, P.M. (2013) Systems Inquiry and Its Application in Education. In: Handbook of Research on Educational Communications and Technology, Springer Science \& Business Media, Berlin, 49-69.

[16] Maglio, P. and Spohrer, J. (2013) A Service Science Perspective on Business Model Innovation. Industrial Marketing Management, 42, 665-670. https://doi.org/10.1016/j.indmarman.2013.05.007

[17] Polese, F., Tommasetti, A., Vesci, M., Carrubo, L. and Troisi, O. (2016) Decision-Making in Smart Service Systems: A Viable Systems Approach Contribution to Service Science Advances. International Conference on Exploring Service Science, Bucharest, 25-27 May 2016, 3-14. https://doi.org/10.1007/978-3-319-32689-4_1

[18] von Bertalanffy, L. and Sutherland, J.W. (1974) General Systems Theory: Foundations, Developments, Applications. IEEE Transactions on Systems, Man, and Cybernetics, SMC-4, 592-592. https://doi.org/10.1109/TSMC.1974.4309376

[19] Fuentes-Zenón, A. (1991) El enfoque de sistemas en la solución de problemas. La elaboración del modelo conceptual. Universidad Nacional Autónoma de México.

[20] Ackoff, R. (1981) Creating the Corporate Future: Plan or Be Planned for. University of Texas Press, Austin.

[21] Churchman, C. (1979) El enfoque de sistemas. Diana.

[22] Checkland, P. (1999) Systems Thinking, Systems Practice. In: Currie, W.L. and Galliers, B., Eds., Rethinking Management Information Systems, Oxford University Press, Oxford, 45-56.

[23] Abrahamsson, M. and Akan Aronsson, H. (1999) Measuring Logistics Structure. International Journal of Logistics Research and Applications, 2, 263-284. https://doi.org/10.1080/13675569908901585 